\title{
Is time preference and present bias associated with the decision to start, quit or maintain physical activity over time?
}

\author{
Barbara Eberth $^{1}$ (D) Marjon van der Pol $^{2}$ (D) $\cdot$ Dmitri Kemenev $^{3}$
}

Received: 27 February 2020 / Accepted: 5 June 2020 / Published online: 16 June 2020

(C) The Author(s) 2020

\begin{abstract}
Aim It is commonly observed that individuals transition into and out of physical activity behaviours over time. A better understanding of the determinants of these transitions is important in order to develop effective interventions. Our focus is on examining the role of time preference and present bias (how present or future oriented individuals are) in the decision to start, quit and maintain physical activity over time.

Subject and methods We examine changes in different types of physical activity participation over time, allowing us to distinguish between physical activity initiation versus maintenance. We use data from the National Longitudinal Survey of Youth 1979 (NLSY79).

Results We show that present bias impacts maintenance but not initiation of physical activity behaviour. The time preference rate impacts maintenance of strengthening exercise in men only.

Conclusion The results of our study suggest that interventions aimed at overcoming present bias, such as commitment devices in the form of deposit contracts, may be effective in maintaining physical activity but not initiating physical activity.
\end{abstract}

Keywords Time preference $\cdot$ Physical activity

\section{Introduction}

Despite the well-known benefits of a healthy lifestyle, tackling the adverse health effects of unhealthy lifestyles remains a major public health policy concern and requires careful consideration in designing effective interventions that also recognise the importance of individual preferences. The role of time preference (how future or present oriented an individual is) in

Electronic supplementary material The online version of this article (https://doi.org/10.1007/s10389-020-01334-8) contains supplementary material, which is available to authorized users.

Barbara Eberth

barbara.eberth@ncl.ac.uk

1 Newcastle University Business School, 5 Barrack Road, Newcastle upon Tyne NE1 4SE, UK

2 Health Economics Research Unit, University of Aberdeen, Polwarth Building, Foresterhill, Aberdeen AB25 2ZD, UK

3 BaseCase, Charlottenstr. 16, 10117 Berlin, Germany the individual's decision to invest in their health is increasingly recognised. Health investments generally represent a tradeoff between more immediate costs and longer-term benefits. For example, physical activity is associated with immediate costs such as financial and time costs and delayed benefits such as increases in life expectancy. Time preferences will, therefore, influence the decision whether to be physically active. More present-oriented individuals who have high time preference rates will invest less in their health relative to more future-oriented individuals who have low time preference rates, as they place a higher value on the immediate costs and a lower value on the future benefits. A growing body of evidence shows that an individual's rate of time preference is associated with a range of unhealthy behaviours, such as smoking, alcohol and drug use (Barlow et al. 2016, 2017; Story et al. 2014). Evidence also suggests that individuals are present biased. Individuals who are present biased will place a high value on immediate costs (Frederick et al. 2002). They may, therefore, plan to be physically active next week (as the costs occur in the future) but they will fail to follow through with this when next week arrives (as the costs 
are now immediate). The role of present bias in health behaviours has been explored to a more limited extent (Bradford 2010; Grignon 2009; Ikeda et al. 2010; Mørkbak et al. 2017).

Most previous studies examining time preference and health behaviours have used cross-sectional data. These studies provide useful insights into the relationship between time preferences and health behaviours at a single point in time. However, individuals often change their health behaviours over time. Some individuals become physically active early in life but stop again quickly, others stay physically active throughout their life, some stop but become active again in middle or later life due to health concerns etc. Examining these patterns of changes in health behaviours require longitudinal data. Longitudinal data allow us to examine the determinants (such as time preference and present bias) of initiation and maintenance of health behaviours over time, which can be modelled as transitions between states (Sutton 2018). A better understanding of these transitions (the decisions to quit, start or continue to invest in health) is important in order to devise interventions that reduce transitions out of health investments and increase transitions into health investments. Longitudinal data also increase our ability to determine whether time preferences influence health behaviours or whether health behaviours influences time preferences.

This paper focuses on the question of whether time preference and present bias play a role in transitions in physical activity behaviour. Physical activity is an important component of an individuals' healthy lifestyle and is a behaviour that many individuals transition in and out of over time. Costs and benefits of physical activity change over the lifetime, often in an unexpected way, for example, due to changes in work or family commitments, health shocks, changes in the availability of leisure facilities etc. The impact of changes in costs and benefits on an individual's decision to participate in physical activity in each time period will depend on their time preference rate and present bias. Individuals' rates of time preference have been shown to be correlated with physical activity in crosssectional studies (Adams and Nettle 2009; Bradford 2010; Chabris et al. 2008; Daugherty and Brase 2010; Hunter et al. 2018; Kosteas 2015; Shuval et al. 2017) but no previous studies have examined time preference rates and changes in physical activity over time. There is less evidence on the relationship between present bias and physical activity (Hunter et al. 2018; Bradford et al. 2014) and, again, no studies have examined present bias and changes in physical activity. The study by Grignon (2009) is interesting in the context of the current paper, as they explored the role of present bias in the decision to start and quit smoking. They find that present bias does not predict smoking initiation but present-biased individuals do quit later in life and attempt to quit smoking more often.

This is the first study to examine the role of time preference and present bias in the decision to start, quit and maintain physical activity participation over time. The empirical analysis uses longitudinal data from a large US survey, namely, the National Longitudinal Survey of Youth 1979 (NLSY79).

\section{Methods}

\section{Hypotheses}

This study examines the role of time preference and present bias in transitions (changes) in physical activity behaviour over time. Individuals may change their physical activity behaviour if the costs and benefits change over time. The impact of these changes on physical activity behaviour will depend on an individual's time preference rate and present bias. For example, inactive individuals will transition to being active if the benefits start to outweigh the costs of physical activity. This requires relatively larger decreases in immediate costs and/or relatively larger increases in future benefits in individuals who are present biased and/or have a relatively high time preference rate given the relatively low value they place on future benefits versus immediate costs. It is, therefore, hypothesised that:

1. Individuals with high time preference rates (more present oriented) are more likely to transition from active to inactive and less likely to transition from inactive to active.

2. Individuals who are present biased are more likely to transition from active to inactive and less likely to transition from inactive to active.

\section{Data}

We use data from four waves (2006, 2008, 2010 and 2012) of the NLSY1979. The panel consists of 12,686 randomly selected individuals born between 1954 and 1964 who were first interviewed aged 14-21 years in 1979. The sample was designed to represent young individuals living in the United States, consisting of a randomly selected sample of 6111 individuals and a supplementary sample of 5295 Hispanic, black and disadvantaged minority and 1280 military youth. The questionnaire covers several life aspects, including participation in physical activity. Time preferences were collected in the 2006 wave. Our estimation samples include individuals for whom time preference and physical activity data were available. The 2006, 2008, 2010 and 2012 NLSY79 samples consist of $7654,7757,7565$ and 7301 respondents, respectively. The physical activity indicators from the 2006 wave are used in the analysis as a lag indicator of physical activity participation for 2008 . Therefore, the main estimation samples are derived from the 2008, 2010 and 2012 waves. Over the 
estimation period, this resulted in an estimation sample of 6038 individuals.

\section{Measures}

\section{Physical activity}

The questionnaire categorises physical activity into three types: strengthening activity, light/moderate activity and vigorous activity. The following questions were used to derive the binary physical activity participation indicators:

"How often do you do vigorous activities for at least 10 minutes that cause heavy sweating or large increases in breathing or heart rate?"

"How often do you do light or moderate activities for at least 10 minutes that cause only light sweating or slight to moderate increase in breathing or heart rate?"

"How often do you do physical activities specifically designed to strengthen your muscles, such as lifting weights or doing calisthenics? (Include all such activities, even if you have mentioned them before.)"

These questions were followed by a question regarding the period over which the activity took place (per day, per week, per month or per year). If respondents stated that they participate in vigorous and light/moderate activity, they were subsequently asked the participation duration on each occasion in hours and minutes. A small number of respondents returned a zero duration and these were coded as not participating ${ }^{1}$.

Strength activity can be broadly defined as sporting physical activity and is our preferred measure to capture leisure time physical activity. The other two physical activity questions can include any type of physical activity, such as walking or physical activity at work. As individuals may substitute between the different types of physical activity, we also derived a summary indicator for participation in any of these three activity types, as some individuals may participate in more than one of the physical activity categories described above.

\section{Time preference}

The 2006 survey included two hypothetical questions to elicit time preference for monetary outcomes. The first question asked for a monetary trade-off between now and a 1-year delay:

\footnotetext{
${ }^{1}$ Five respondents in the case of vigorous and two respondents in the case of light/moderate activity.
}

"Suppose you have won a prize of $\$ 1000$, which you can claim immediately. However, you have the alternative of waiting 1 year to claim the prize. If you do wait, you will receive more than $\$ 1000$. What is the smallest amount of money in addition to the $\$ 1000$ you would have to receive 1 year from now to convince you to wait rather than claim the prize now?"

The second question is identical but offers a trade-off between now and a monthly delay. In line with Courtemanche et al. (2015), we assume a quasi-hyperbolic model (Laibson 1997) and estimate time preference rate $(\rho)$ as $\rho=\left(\frac{1000+x 1}{1000+x 2}\right)^{\frac{12}{11}}-1$ and present bias $(\beta)$ as $\beta=\frac{1000}{(1+\rho)^{-1} \times(1000+x 1)}$, where $x 1$ is the response amount in the first question (1-year delay) and $x 2$ is the response amount in the second question (1-month delay). Some respondents indicated extremely large money amounts to wait (e.g. \$1 million for a 1-year delay). To deal with the possible inconsistency of the estimator caused by such outliers, we excluded the top $1 \%$ of the distribution of the responses to the two questions, respectively.

\section{Covariates}

We control for a set of demographic, human capital, labour and income characteristics which are thought to influence physical activity participation. Demographic characteristics include gender, age, marital status and ethnic origin. These have previously been shown to be significant determinants of physical activity behaviour (Downward et al. 2011; Eberth and Smith 2010; Farrell and Shields 2002; Humphreys and Ruseski 2011; Lechner 2009). The human capital indicators include education and the percentile score of the Armed Forces Qualification Test (AFQT); the latter is thought to proxy cognitive ability and was measured in 1981. Both are expected to significantly and positively impact physical activity participation (Eberth and Smith 2010; Hovemann and Wicker 2009; Humphreys and Ruseski 2011), potentially through the higher knowledge of physical activity health benefits. Education is categorised into: less than a high school education, high school education but no college, college but less than a four-year college degree education and college degree or higher. The labour market characteristics control for occupational status and the number of hours worked. These factors reflect leisure time availability and, thus, proxy for opportunity cost of time. Occupational status is categorised as white collar, blue collar, service occupations and not in paid employment, which serves as the reference category. Number of hours worked is based on the self-reported average number of hours worked per week. We further 
control for a quadratic in income measured as the total net family income in the previous year.

\section{Analyses}

We can think of an individual's physical activity participation decision in the following way. The individual has to decide whether to be physically active today or not and then repeats this decision on each consecutive day in the future. In our data, we observe these transitions in discrete time biannually rather than daily. Assuming individual $i$ is observed to either participate or not at time $t$, we can formally describe the participation/non-participation history by defining a binary variable as:

$d_{i t}= \begin{cases}1 & \text { if participating } \\ 0 & \text { otherwise }\end{cases}$

$i=1,2, \ldots, N ; t=1,2, \ldots, T$.

Participation at date $t$ likely depends on participation at $t-$ 1. The conditional probabilities of participation at date $t$ given participation or not at $t-1$ can be illustrated in a Markov transition matrix:

$T=\left[\begin{array}{ll}P\left(d_{i t}=0 \mid d_{i, t-1}=0\right) & P\left(d_{i t}=1 \mid d_{i, t-1}=0\right) \\ P\left(d_{i t}=0 \mid d_{i, t-1}=1\right) & P\left(d_{i t}=1 \mid d_{i, t-1}=1\right)\end{array}\right]$

This matrix illustrates the stochastic process of an individual being in either the participation or no participation state at $t$ -1 , remaining in that state or transiting to the other state at time $t$. See Online Resource 1 for estimation of the conditional probabilities.

The model is estimated using a random effects probit model, where the latent variable model is of the form:

$$
\begin{aligned}
& d_{i t}^{*}=x_{i t}^{\prime} \delta+\gamma d_{i t-1}+\theta x_{i t}^{\prime} \times d_{i t-1}+\varepsilon_{i t} \\
& d_{i t}=1\left(d_{i t}^{*}>0\right) \\
& P\left(d_{i t}=1\right)=x_{i t}^{\prime} \delta+\gamma d_{i t-1}+\theta x_{i t}^{\prime} \times d_{i t-1} \quad i=1, \ldots, N ; t=2, \ldots, T_{i}
\end{aligned}
$$

Inclusion of the lagged participation term, $d_{i t-1}$, acts to shift the intercept between the participation and no participation probability. We further relax the assumption of equal but opposite effects of the covariates $x_{i t}$ on the participation and no participation probabilities by introducing an interaction term between all covariates $x_{i t}$ and the intercept shift term, $x_{i t} \times d_{i t-1}$ (Barmby 1998). Time preference and present bias enter the model as covariates, $x_{i t}$, such that, in estimation, the parameter vectors $\delta_{0}$ and $\delta_{1}$ include the time preference $(\beta)$ and present bias $(\rho)$ parameters of interest. Equation (3) is estimated in STATA using the xtprobit command with robust standard errors.

The estimation starts with a basic model, where only the present bias $(\beta)$ and time preference rate $(\rho)$ parameters are estimated. We then consecutively add and control for the demographic, human capital, labour, income and risk covariates.

\section{Results}

Table 1 shows reported physical activity patterns for our estimation sample over time and by physical activity type. This
Table 1 Summary statistics: type

\begin{tabular}{|c|c|c|c|c|c|c|}
\hline & \multicolumn{2}{|l|}{ All } & \multicolumn{2}{|l|}{ Male } & \multicolumn{2}{|l|}{ Female } \\
\hline & Frequency & $\%$ & Frequency & $\%$ & Frequency & $\%$ \\
\hline Type of reported participation spell & \multicolumn{6}{|c|}{ Strengthening exercise } \\
\hline Never participated & 2312 & 38.64 & 1020 & 35.48 & 1292 & 41.57 \\
\hline Intermittent participation & 2585 & 43.20 & 1205 & 41.92 & 1380 & 44.40 \\
\hline \multirow[t]{2}{*}{ Always participated } & 1086 & 18.15 & 650 & 22.61 & 436 & 14.03 \\
\hline & \multicolumn{6}{|c|}{ Light/moderate physical activity } \\
\hline Never participated & 391 & 7.08 & 215 & 8.10 & 176 & 6.13 \\
\hline Intermittent participation & 2517 & 45.56 & 1253 & 47.23 & 1264 & 44.31 \\
\hline \multirow[t]{2}{*}{ Always participated } & 2617 & 47.37 & 1185 & 44.67 & 1432 & 49.86 \\
\hline & \multicolumn{6}{|c|}{ Vigorous physical activity } \\
\hline Never participated & 690 & 12.18 & 259 & 9.56 & 431 & 14.95 \\
\hline Intermittent participation & 2429 & 42.87 & 1030 & 38.01 & 1399 & 47.34 \\
\hline \multirow[t]{2}{*}{ Always participated } & 2546 & 44.94 & 1421 & 52.44 & 1125 & 61.93 \\
\hline & \multicolumn{6}{|c|}{ Any physical activity } \\
\hline Never participated & 156 & 2.58 & 75 & 2.58 & 81 & 2.58 \\
\hline Intermittent participation & 1651 & 27.35 & 733 & 25.24 & 918 & 29.29 \\
\hline Always participated & 4231 & 70.07 & 2096 & 72.18 & 2135 & 68.12 \\
\hline
\end{tabular}
of reported physical activity spells, 2008-2012 
table summarises decisions made by individuals to never participate (reported non-participation in all three waves), participate intermittently (reported participation in one or two waves) and to always participate in physical activity (reported participation in all three waves). Intermittent participation is $43.2 \%$ for strengthening exercise, $45.6 \%$ for light/moderate physical activity and $42.9 \%$ for vigorous physical activity. A common feature across the three physical activity types is that a substantial proportion of individuals start or quit participation over the study period.

The bottom panel of Table 1 summarises participation spells for our summary participation measure that accounts for participation in strengthening, light/moderate and vigorous physical activity (any physical activity). 2.6\% of individuals reported to have never participated in any physical activity, $27.4 \%$ reported to have participated in physical activity in one or two waves and $70.1 \%$ reported participation in all three waves. Participation rates across all waves in any physical activity are high. $72.2 \%$ of men reported participation in all three waves compared to $68 \%$ of women. $25.2 \%$ of men reported to have engaged in any physical activity in one or two waves compared to $29.3 \%$ of women.

A feature that stands out across the three physical activity types is that regular participation in light/moderate and vigorous activity is higher in both men and women compared to participation in strengthening exercise. For instance, $18.2 \%$ of respondents regularly participate in strengthening exercise (22.6\% of men and $14.0 \%$ of women), which compares to $47.4 \%$ for light/moderate $(44.7 \%$ of men and $49.7 \%$ of women) and $45 \%$ for vigorous physical activity (52.4\% of men and $62 \%$ of women). For strengthening exercise, we further find the highest non-participation rates compared to light/moderate and vigorous physical activity participation. Overall, the reported participation spells show the complexity of decisions made by individuals over their physical activity participation.

Descriptive statistics of the sample are shown in Table 2 and the Appendix and are based on all individuals with nonmissing physical activity and time preference values. The mean present bias $(\beta)$ for the whole sample is 0.777 , indicating that the sample is, on average, present biased. The mean annual time preference rate $(\rho)$ is 0.879 .

The model results are presented in Tables 3, 4 and 5. The top part of each table presents the determinants of transitions from no participation in physical activity to participation in physical activity, i.e. initiation of physical activity. The lower part of each table presents the determinants of transitions from participation in physical activity to no participation in physical activity, that is, failure to maintain physical activity participation.

We hypothesised that individuals with high time preference rates $(\rho)$ are more likely to transition from physical activity to inactivity (maintenance failure) and less likely to transition from physical inactivity to activity (initiation). We find no

Table 2 Descriptive statistics

\begin{tabular}{|c|c|c|c|c|}
\hline Variable & Mean & Standard deviation & Min & Max \\
\hline Present bias $(\beta)$ & 0.777 & 0.213 & 0.164 & 1.319 \\
\hline Time preference rate $(\rho)$ & 0.879 & 1.880 & -0.806 & 31.039 \\
\hline Age (years) & 49.408 & 2.818 & 44 & 56 \\
\hline Female & 0.519 & 0.500 & 0 & 1 \\
\hline Hispanic ethnic background & 0.185 & 0.388 & 0 & 1 \\
\hline Black ethnic background & 0.300 & 0.458 & 0 & 1 \\
\hline White ethnic background & 0.514 & 0.500 & 0 & 1 \\
\hline Married & 0.566 & 0.496 & 0 & 1 \\
\hline AFQT & 40.418 & 29.032 & 1 & 99 \\
\hline Less than high school & 0.092 & 0.289 & 0 & 1 \\
\hline High school & 0.424 & 0.494 & 0 & 1 \\
\hline Some college & 0.244 & 0.430 & 0 & 1 \\
\hline College & 0.240 & 0.427 & 0 & 1 \\
\hline White collar & 0.499 & 0.500 & 0 & 1 \\
\hline Blue collar & 0.204 & 0.403 & 0 & 1 \\
\hline Service & 0.114 & 0.317 & 0 & 1 \\
\hline Not in paid employment & 0.184 & 0.387 & 0 & 1 \\
\hline Hours worked & 32.824 & 20.319 & 0 & 96 \\
\hline Total household income $(\$ 10,000)$ & 7.659 & 7.815 & 0 & 49.78 \\
\hline $\begin{array}{l}\text { Risk (amount to forego } 50 \% \text { chance } \\
\text { of } \$ 10,000 \text { or zero) }\end{array}$ & 4812.260 & 3400.625 & 0 & 10,000 \\
\hline
\end{tabular}

AFQT, Armed Forces Qualification Test 
Table 3 Strengthening exercise participation

\begin{tabular}{|c|c|c|c|c|c|c|}
\hline & Model 1 & Model 2 & Model 4 & Model 4 & Model 5 & Model 6 \\
\hline \multicolumn{7}{|l|}{ All } \\
\hline \multicolumn{7}{|l|}{ Initiation $^{\mathrm{a}}$} \\
\hline$\beta$ & 0.085 & 0.106 & 0.018 & 0.011 & 0.023 & 0.050 \\
\hline$\rho$ & -0.001 & -0.002 & -0.001 & 0.000 & 0.001 & -0.001 \\
\hline \multicolumn{7}{|c|}{ Maintenance failure ${ }^{\mathrm{b}}$} \\
\hline$\beta$ & $-0.272 * * *$ & $-0.177^{*}$ & -0.104 & -0.107 & $-0.141^{*}$ & $-0.123 *$ \\
\hline$\rho$ & 0.010 & 0.008 & 0.005 & 0.004 & 0.008 & 0.011 \\
\hline No. & 17,892 & 17,892 & 17,270 & 17,009 & 14,868 & 14,353 \\
\hline Log-likelihood & $-10,500$ & $-10,400$ & -9956.43 & -9791.62 & -8523.48 & -8233.64 \\
\hline$x^{2}$ & 2884.149 & 2975.597 & 3009.18 & $2.98 \mathrm{E}+03$ & $2.69 \mathrm{E}+03$ & 2602.056 \\
\hline \multicolumn{7}{|l|}{ Women } \\
\hline \multicolumn{7}{|l|}{ Initiation $^{\mathrm{a}}$} \\
\hline$\beta$ & 0.132 & 0.113 & 0.031 & 0.031 & 0.029 & 0.079 \\
\hline$\rho_{\mathrm{h}}$ & -0.009 & -0.009 & -0.010 & -0.009 & -0.007 & -0.010 \\
\hline \multicolumn{7}{|c|}{ Maintenance failure ${ }^{\mathrm{b}}$} \\
\hline$\beta$ & $-0.460 * * *$ & $-0.322 * * *$ & $-0.254 * *$ & $-0.263^{* *}$ & $-0.346^{*}$ & $-0.327 * *$ \\
\hline$\rho$ & -0.007 & -0.008 & -0.012 & -0.013 & -0.002 & 0.005 \\
\hline No. & 9284 & 9284 & 9032 & 8924 & 7768 & 7445 \\
\hline Log-likelihood & -5413.62 & -5390.25 & -5195.97 & -5128 & -4427.64 & -4248.73 \\
\hline$x^{2}$ & 1180.935 & 644.225 & 873.008 & 910.572 & 1002.42 & 954.223 \\
\hline \multicolumn{7}{|l|}{ Men } \\
\hline \multicolumn{7}{|l|}{ Initiation $^{\mathrm{a}}$} \\
\hline$\beta$ & 0.009 & 0.092 & -0.005 & -0.029 & -0.009 & -0.014 \\
\hline$\rho_{\mathrm{h}}$ & 0.007 & 0.003 & 0.005 & 0.007 & 0.007 & 0.005 \\
\hline \multicolumn{7}{|c|}{ Maintenance failure ${ }^{\mathrm{b}}$} \\
\hline$\beta$ & -0.070 & -0.055 & 0.012 & 0.039 & 0.070 & 0.081 \\
\hline$\rho$ & $0.027 * *$ & $0.024 * *$ & $0.025 * *$ & $0.023 * *$ & $0.021^{*}$ & $0.021 *$ \\
\hline No. & 8608 & 8608 & 8238 & 8085 & 7100 & 6908 \\
\hline Log-likelihood & -5012.87 & -4991.24 & -4724.5 & -4611.75 & -4052.72 & -3944.6 \\
\hline$x^{2}$ & 1662.355 & 1692.059 & 1690.354 & 1692.959 & 1498.251 & 1458.744 \\
\hline
\end{tabular}

${ }^{\mathrm{a}}$ From no participation to participation: $d_{i t}=1 \mid d_{i t-1}=0$

${ }^{\mathrm{b}}$ From participation to no participation: $d_{i t}=0 \mid d_{i t-1}=1$

Model 1: $\beta$ and $\rho_{\mathrm{h}}$ only; Model 2: $\beta$ and $\rho_{\mathrm{h}}$ and demographics; Model 3: $\beta$ and $\rho_{\mathrm{h}}$, demographics and human capital; Model 4: $\beta$ and $\rho_{\mathrm{h}}$, demographics, human capital and labour; Model 5: $\beta$ and $\rho_{\mathrm{h}}$, demographics, human capital, labour and income; Model 6: $\beta$ and $\rho_{\mathrm{h}}$, demographics, human capital, labour, income and risk

$* * * p<0.01, * * p<0.05, * p<0.10$

evidence that the time preference rate $(\rho)$ significantly impacts the likelihood of physical activity initiation or maintenance failure across the three physical activity participation types.

We hypothesised that individuals who are present biased $(\beta<1)$ are more likely to transition from physical activity to inactivity (maintenance failure) and less likely to transition from being inactive to active (initiation). The results show that present bias $(\beta)$ impacts maintenance failure of physical activity participation but not initiation. This holds for all three physical activity types. The present bias coefficient for maintenance failure is negative, suggesting that the more present biased (the lower the value of $\beta$ ), the higher the probability that individuals will fail to maintain physical activity participation. The size of the coefficient generally reduces as we move from specification (1) to specification (5), but remains statistically significant at a $10 \%$ level.

The gender subgroup analysis for the three physical activity types reveals that the time preference rate $(\rho)$ affects maintenance failure of physical activity participation in men but not in women. Men with higher rates of time preference are less likely to maintain physical activity participation behaviour. Present bias $(\beta)$ significantly impacts maintenance failure of 
Table 4 Low/moderate physical activity participation

\begin{tabular}{|c|c|c|c|c|c|c|}
\hline & Model 1 & Model 2 & Model 3 & Model 4 & Model 5 & Model 6 \\
\hline \multicolumn{7}{|l|}{ All } \\
\hline \multicolumn{7}{|l|}{ Initiation $^{\mathrm{a}}$} \\
\hline$\beta$ & $0.327 * * *$ & -0.870 & -0.164 & -0.151 & -0.183 & -0.186 \\
\hline$\rho$ & 0.161 & $0.021 * *$ & $0.020 *$ & $0.020^{*}$ & 0.125 & 0.009 \\
\hline \multicolumn{7}{|c|}{ Maintenance failure ${ }^{\mathrm{b}}$} \\
\hline$\beta$ & $-0.374 * * *$ & $-0.218^{*}$ & $-0.125^{*}$ & $-0.113^{*}$ & $-0.105^{*}$ & $-0.121^{*}$ \\
\hline$\rho$ & $0.014 * *$ & 0.006 & 0.006 & 0.005 & 0.006 & 0.009 \\
\hline No. & 16,770 & 16,770 & 16,188 & 15,951 & 13,963 & 13,498 \\
\hline Log-likelihood & -9031.3 & -8896.89 & -8509.18 & -8372.5 & -7246.61 & -7000.46 \\
\hline$x^{2}$ & 246.137 & 640.55 & 759.778 & 802.93 & 802.571 & 758.073 \\
\hline \multicolumn{7}{|l|}{ Women } \\
\hline \multicolumn{7}{|l|}{ Initiation $^{\mathrm{a}}$} \\
\hline$\beta$ & 0.126 & -0.005 & -0.082 & -0.081 & -0.175 & -0.207 \\
\hline$\rho$ & 0.018 & 0.018 & 0.017 & 0.017 & 0.011 & 0.003 \\
\hline \multicolumn{7}{|c|}{ Maintenance failure ${ }^{\mathrm{b}}$} \\
\hline$\beta$ & -0.408 & $-0.223 * *$ & -0.079 & -0.064 & -0.050 & -0.074 \\
\hline$\rho$ & 0.008 & 0.006 & 0.007 & 0.006 & 0.012 & $0.017 *$ \\
\hline No. & 8692 & 8692 & 8455 & 8353 & 7277 & 6982 \\
\hline Log-likelihood & -4497.22 & -4427.984 & -4252.81 & -4192.55 & -3621.33 & -3470.27 \\
\hline$x^{2}$ & 153.7 & 365.793 & 467.849 & 499.564 & 488.017 & 454.85 \\
\hline \multicolumn{7}{|l|}{ Men } \\
\hline \multicolumn{7}{|l|}{ Initiation $^{\mathrm{a}}$} \\
\hline$\beta$ & -0.047 & -0.181 & -0.251 & -0.243 & -0.209 & -0.176 \\
\hline$\rho$ & 0.014 & 0.025 & 0.023 & 0.023 & 0.014 & 0.016 \\
\hline \multicolumn{7}{|c|}{ Maintenance failure ${ }^{\mathrm{b}}$} \\
\hline$\beta$ & $-0.377 * * *$ & $-0.212^{*}$ & $-0.171 *$ & $-0.166^{*}$ & $-0.157 *$ & $-0.158^{*}$ \\
\hline$\rho$ & $0.017 * *$ & 0.006 & 0.006 & 0.005 & 0.001 & 0.001 \\
\hline No. & 8078 & 8078 & 7733 & 7598 & 6686 & 6516 \\
\hline Log-likelihood & -4518.97 & -4466.003 & -4241.96 & -4160.97 & -3608.52 & -3511.35 \\
\hline$x^{2}$ & 103.871 & 253.845 & 297.403 & 318.226 & 326.868 & 318.608 \\
\hline
\end{tabular}

See notes for Table 3

strengthening and vigorous activity participation in women and light/moderate and vigorous activity participation in men.

In terms of the covariates, marital status, cognitive ability, ethnicity, education, employment, hours of work and income play a role in some but not all models. As individuals may substitute between the different physical activity types, we also examined participation in any type of activity as a robustness check. Table 6 shows that the results for any physical activity are in line with the results for the three physical activity types when examined at separately. Present bias $(\beta)$ impacts maintenance failure but not initiation. There is no evidence to suggest that the time preference rate $(\rho)$ significantly impacts the likelihood of any physical activity initiation or maintenance failure across the three physical activity participation types for the overall samples.
The time preference measures were collected in the 2006 wave only and the analysis, therefore, implicitly assumes that the time preference parameters remain stable over the four waves. This assumption is more likely to hold over shorter time periods and we, therefore, rerun the analysis using the 2008 data only. The results (available from the authors) are very similar and again show that present bias is associated with maintenance but not with uptake of physical activity.

\section{Discussion}

This paper examined the relationship between quasihyperbolic discounting and transitions in physical activity behaviour. We find no evidence that the time preference rate 
Table 5 Vigorous physical activity participation

\begin{tabular}{|c|c|c|c|c|c|c|}
\hline & Model 1 & Model 2 & Model 3 & Model 4 & Model 4 & Model 6 \\
\hline \multicolumn{7}{|l|}{ Initiation $^{\mathrm{a}}$} \\
\hline$\beta$ & 0.039 & -0.023 & -0.118 & -0.118 & -0.140 & -0.157 \\
\hline$\rho$ & 0.009 & 0.012 & 0.012 & 0.015 & $0.021 * *$ & $0.019^{*}$ \\
\hline \multicolumn{7}{|c|}{ Maintenance failure ${ }^{\mathrm{b}}$} \\
\hline$\beta$ & $-0.328 * * *$ & -0.159 & -0.031 & -0.016 & -0.075 & $-0.126^{*}$ \\
\hline$\rho$ & $0.011 * *$ & 0.006 & 0.002 & 0.001 & -0.001 & 0.002 \\
\hline No. & 17,151 & 17,151 & 16,562 & 16,313 & 14,271 & 13,775 \\
\hline Log-likelihood & -9581.658 & -9456.974 & -8970.649 & -8798.455 & -7538.419 & -7249.962 \\
\hline$x^{2}$ & 573.878 & 1070.678 & 1440.376 & 1560.766 & 1653.989 & 1591.142 \\
\hline \multicolumn{7}{|l|}{ Women } \\
\hline \multicolumn{7}{|l|}{ Initiation $^{\mathrm{a}}$} \\
\hline$\beta$ & -0.004 & -0.04 & -0.13 & -0.127 & -0.122 & -0.139 \\
\hline$\rho$ & 0.02 & $0.021 *$ & 0.018 & 0.021 & 0.023 & 0.016 \\
\hline \multicolumn{7}{|c|}{ Maintenance failure ${ }^{\mathrm{b}}$} \\
\hline$\beta$ & $-0.331 * * *$ & $-0.166^{* *}$ & 0.003 & 0.004 & -0.079 & $-0.145^{*}$ \\
\hline$\rho$ & 0.005 & 0.003 & 0.001 & 0.001 & 0.003 & 0.011 \\
\hline No. & 8911 & 8911 & 8673 & 8568 & 7461 & 7151 \\
\hline Log-likelihood & -5312.939 & -5264.536 & -5050.195 & -4978.353 & -4273.001 & -4088.441 \\
\hline$x^{2}$ & 288.682 & 494.309 & 696.259 & 737.643 & 813.877 & 781.179 \\
\hline \multicolumn{7}{|l|}{ Men } \\
\hline \multicolumn{7}{|l|}{ Initiation $^{\mathrm{a}}$} \\
\hline$\beta$ & 0.09 & 0.005 & -0.077 & -0.098 & -0.19 & -0.196 \\
\hline$\rho$ & -0.006 & 0.003 & 0.004 & 0.01 & 0.021 & 0.023 \\
\hline \multicolumn{7}{|c|}{ Maintenance failure ${ }^{\mathrm{b}}$} \\
\hline$\beta$ & $-0.270 * * *$ & $-0.157^{*}$ & -0.077 & -0.034 & -0.068 & -0.097 \\
\hline$\rho$ & $0.018^{*}$ & 0.010 & 0.005 & 0.003 & -0.004 & -0.005 \\
\hline No. & 8240 & 8240 & 7889 & 7745 & 6810 & 6624 \\
\hline Log-likelihood & -4220.218 & -4181.515 & -3903.644 & -3780.836 & -3228.87 & -3124.768 \\
\hline$x^{2}$ & 222.513 & 371.279 & 582.637 & 734.266 & 738.669 & 711.165 \\
\hline
\end{tabular}

See notes for Table 3

significantly impacts the likelihood of physical activity initiation or maintenance failure across the three physical activity participation types. We find evidence that present bias matters for maintenance failure of physical activity participation but not for initiation of physical activity. The effect of present bias on maintenance failure is reduced when controlling for other covariates. The basic results are in line with those from Grignon (2009), who showed that present bias did not predict initiation of smoking but did predict maintenance (quit attempts). It may be the case that other factors are more important for initiation. Other biases such as habit formation have been shown to be important in explaining and predicting physical activity behaviour (Humphreys et al. 2015). It may also be the case that, for initiation, a distinction needs to be made between naïve and sophisticated present bias (Laibson 1997). Sophisticates realise that they are present biased and know that they will not follow through with plans they have made, whilst naïves do not realise that they are present biased and expect to carry out plans that they have made. This suggests that a naïve present-biased individual will make no effort to constrain their future behaviour because they believe that, when the time comes, they will behave in a time-consistent fashion. A sophisticated present-biased individual, on the other hand, will make some effort to constrain her future self to behave in a more time-consistent fashion. Sophisticated present-biased individuals may, therefore, be more likely to transition from physical inactivity to activity, as they make use of commitment devices. Measuring sophistication about present bias is challenging and no suitable measures were available in the data used for this paper. Testing the impact of sophistication on transitions in physical activity behaviour would be an interesting line of future enquiry. 
Table 6 Any physical activity participation

\begin{tabular}{|c|c|c|c|c|c|c|}
\hline & Model 2 & Model 2 & Model 3 & Model 4 & Model 5 & Model 6 \\
\hline \multicolumn{7}{|l|}{ All } \\
\hline \multicolumn{7}{|l|}{ Initiation $^{\mathrm{a}}$} \\
\hline$\beta$ & 0.183 & 0.096 & 0.023 & 0.050 & -0.024 & -0.045 \\
\hline$\rho$ & 0.010 & 0.016 & 0.015 & 0.014 & 0.019 & 0.017 \\
\hline \multicolumn{7}{|c|}{ Maintenance failure ${ }^{\mathrm{b}}$} \\
\hline$\beta$ & $-0.400 * * *$ & -0.236 & -0.095 & -0.090 & -0.093 & $-0.131^{*}$ \\
\hline$\rho$ & -0.001 & -0.007 & -0.006 & -0.007 & -0.010 & -0.006 \\
\hline No. & 18,114 & 18,114 & 17,487 & 17,221 & 15,046 & 14,517 \\
\hline Log-likelihood & -6920.00 & -6830.00 & -6440.00 & -6330.00 & -5330.00 & -5100.00 \\
\hline$x^{2}$ & 312.396 & 609.659 & 886.585 & 945.220 & 965.443 & 940.245 \\
\hline \multicolumn{7}{|l|}{ Women } \\
\hline \multicolumn{7}{|l|}{ Initiation $^{\mathrm{a}}$} \\
\hline$\beta$ & $0.346^{*}$ & 0.270 & 0.180 & 0.212 & 0.123 & 0.049 \\
\hline$\rho$ & 0.015 & 0.018 & 0.016 & 0.014 & 0.032 & 0.020 \\
\hline \multicolumn{7}{|c|}{ Maintenance failure ${ }^{\mathrm{b}}$} \\
\hline$\beta$ & $-0.341 * * *$ & $-0.167^{*}$ & 0.001 & 0.009 & -0.030 & -0.079 \\
\hline$\rho$ & -0.008 & -0.011 & -0.010 & -0.010 & -0.008 & -0.001 \\
\hline No. & 9402 & 9402 & 9150 & 9040 & 7866 & 7535 \\
\hline Log-likelihood & -3769.107 & -3717.176 & -3534.183 & -3483.322 & -2941.563 & -2799.684 \\
\hline$x^{2}$ & 124.028 & 276.348 & 442.295 & 470.267 & 473.854 & 449.997 \\
\hline \multicolumn{7}{|l|}{ Men } \\
\hline \multicolumn{7}{|l|}{ Initiation $^{\mathrm{a}}$} \\
\hline$\beta$ & -0.016 & -0.112 & -0.161 & -0.173 & -0.224 & -0.154 \\
\hline$\rho$ & 0.002 & 0.014 & 0.011 & 0.012 & 0.004 & 0.012 \\
\hline \multicolumn{7}{|c|}{ Maintenance failure ${ }^{\mathrm{b}}$} \\
\hline$\beta$ & $-0.440 * * *$ & $-0.313 * * *$ & $-0.207 * *$ & $-0.199 * *$ & -0.156 & $-0.174 *$ \\
\hline$\rho$ & 0.007 & -0.002 & -0.001 & -0.004 & -0.010 & -0.009 \\
\hline No. & 8712 & 8712 & 8337 & 8181 & 7180 & 6982 \\
\hline Log-likelihood & -3140.00 & -3100.00 & -2900.00 & -2820.00 & -2360.00 & -2280.00 \\
\hline$x^{2}$ & 204.38 & 343.58 & 460.26 & 518.53 & 519.21 & 526.91 \\
\hline
\end{tabular}

See notes for Table 3

The wider psychology literature also recognises that the determinants of the decision to take up healthy behaviours may be different from the determinants of the decision to maintain healthy behaviours. van Stralen et al. (2009) argue that expectations regarding future outcomes are more important for initiation, whilst it is the satisfaction with outcomes that is more important for maintenance. This implies that individuals with larger present bias would place more importance on the current satisfaction with outcomes, and this may affect maintenance. However, individuals with larger present bias would also attach less importance on future expectations and it should, therefore, also affect initiation. This should be tested empirically in future research, where data on outcome satisfaction for a given health behaviour are available.

Our study is not without limitations. Firstly, both physical activity and time preferences are likely to have been measured with error. Physical activity is known to suffer from self-report bias and the time preference measures were not incentivised, were elicited using open-ended rather than closed-ended methods and did not incorporate risk preferences. However, it could be argued that any measurement error should not be systematically related to physical activity.

Secondly, an interesting question in the literature refers to whether individuals discount health at the same rate as money (Attema 2012; Attema et al. 2018; Bleichrodt et al. 2016). Data limitations did not allow us to test whether time preferences and present bias are domain dependent. In a recent study, Fredslund et al. (2018) tested for differences in time preference and present bias in the health and financial domains, and concluded that these differences were negligible. Thirdly, while the sample used in this study is larger compared to previous studies and more representative of the 
US population, it is restricted to the 42 to 50 years age group. Therefore, the results cannot necessarily be generalised to other age groups. Further research should explore these relationships in other age groups. Finally, time preference was collected in one wave only and we did not control for physical activity behaviour when participants were younger to infer whether physical activity participation at a young age leads to continued physical activity participation when growing older.

The results of our study suggest that interventions aimed at overcoming present bias, such as commitment devices in the form of deposit contracts, may be effective in maintaining physical activity but not initiating physical activity. The approach taken by Royer et al. (2015) may be promising. In that study, financial incentives are used to encourage non-active individuals to become physically active, and these are followed by commitment contracts in order to maintain the higher physical activity levels. Royer et al. (2015) show that this approach is effective in getting employees who were not members of the company gym previously to start visiting the gym and to maintain this after the incentives are removed by offering a deposit contract. The effectiveness of such a scheme in different populations and countries should be explored in further research.

Acknowledgements The Chief Scientist Office of the Scottish Government Health and Social Care Directorates funds the Health Economics Research Unit. The views expressed in this paper are those of the authors only and not those of the funding body.

Author contributions All authors contributed to the study conception and design. Material preparation, data collection and analysis were performed by Barbara Eberth, Marjon van der Pol and Dmitri Kemenev. The first draft of the manuscript was written by Barbara Eberth and Marjon van der Pol and all authors commented on previous versions of the manuscript. All authors read and approved the final manuscript.

\section{Compliance with ethical standards}

Conflict of interest The authors declare that they have no conflict of interest.

Ethics declaration This article does not contain any studies with human participants or animals performed by any of the authors.

Informed consent Informed consent was obtained from all individual participants included in the study.

\section{Appendix}

Table 7 Descriptive statistics by gender

\begin{tabular}{|c|c|c|c|c|c|c|c|}
\hline \multicolumn{4}{|c|}{ Women } & \multicolumn{4}{|l|}{ Men } \\
\hline Mean & $\begin{array}{l}\text { Standard } \\
\text { deviation }\end{array}$ & Min & Max & Mean & $\begin{array}{l}\text { Standard } \\
\text { deviation }\end{array}$ & Min & $\operatorname{Max}$ \\
\hline
\end{tabular}

\begin{tabular}{|c|c|c|c|c|c|c|c|c|}
\hline Present bias $(\beta)$ & 0.766 & 0.216 & 0.180 & 1.263 & 0.790 & 0.208 & 0.164 & 1.319 \\
\hline Time preference rate $(\rho)$ & 0.882 & 1.863 & -0.731 & 23.961 & 0.876 & 1.897 & -0.806 & 31.039 \\
\hline Age (years) & 49.439 & 2.815 & 44 & 56 & 49.374 & 2.822 & 44 & 56 \\
\hline Hispanic ethnic background & 0.189 & 0.391 & 0 & 1 & 0.181 & 0.385 & 0 & 1 \\
\hline Black ethnic background & 0.300 & 0.458 & 0.0 & 1.0 & 0.301 & 0.459 & 0 & 1 \\
\hline White ethnic background & 0.511 & 0.500 & 0.0 & 1.0 & 0.518 & 0.500 & 0 & 1 \\
\hline Married & 0.544 & 0.498 & 0 & 1 & 0.590 & 0.492 & 0 & 1 \\
\hline AFQT & 39.173 & 27.770 & 1 & 99 & 41.784 & 30.300 & 1 & 99 \\
\hline Less than high school & 0.080 & 0.271 & 0 & 1 & 0.105 & 0.307 & 0 & 1 \\
\hline High school & 0.402 & 0.490 & 0 & 1 & 0.447 & 0.497 & 0 & 1 \\
\hline Some college & 0.274 & 0.446 & 0 & 1 & 0.213 & 0.409 & 0 & 1 \\
\hline College & 0.245 & 0.430 & 0 & 1 & 0.235 & 0.424 & 0 & 1 \\
\hline White collar & 0.594 & 0.491 & 0 & 1 & 0.395 & 0.489 & 0 & 1 \\
\hline Blue collar & 0.066 & 0.249 & 0 & 1 & 0.352 & 0.478 & 0 & 1 \\
\hline Service & 0.119 & 0.324 & 0 & 1 & 0.108 & 0.310 & 0 & 1 \\
\hline Not in paid employment & 0.220 & 0.415 & 0 & 1 & 0.144 & 0.352 & 0 & 1 \\
\hline Hours worked & 28.896 & 19.699 & 0 & 96 & 37.062 & 20.126 & 0 & 96 \\
\hline Total household income $(\$ 10,000)$ & 6.968 & 7.047 & 0 & 49.776 & 8.399 & 8.499 & 0 & 49.776 \\
\hline $\begin{array}{l}\text { Risk (amount to forego } 50 \% \text { chance of } \$ 10,000 \text { or } \\
\text { zero) }\end{array}$ & 4729.084 & 3512.323 & 0 & 10,000 & 4900.786 & 3275.452 & 0 & 10,000 \\
\hline
\end{tabular}


Open Access This article is licensed under a Creative Commons Attribution 4.0 International License, which permits use, sharing, adaptation, distribution and reproduction in any medium or format, as long as you give appropriate credit to the original author(s) and the source, provide a link to the Creative Commons licence, and indicate if changes were made. The images or other third party material in this article are included in the article's Creative Commons licence, unless indicated otherwise in a credit line to the material. If material is not included in the article's Creative Commons licence and your intended use is not permitted by statutory regulation or exceeds the permitted use, you will need to obtain permission directly from the copyright holder. To view a copy of this licence, visit http://creativecommons.org/licenses/by/4.0/.

\section{References}

Adams J, Nettle D (2009) Time perspective, personality and smoking, body mass, and physical activity: an empirical study. Br J Health Psychol 14:83-105

Attema AE (2012) Developments in time preference and their implications for medical decision making. J Oper Res Soc 63:1388-1399

Attema AE, Bleichrodt H, L'Haridon O, Peretti-Watel P, Seror V (2018) Discounting health and money: new evidence using a more robust method. J Risk Uncertain 56:117-140. https://doi.org/10.1007/ s11166-018-9279-1

Barlow P, Reeves A, McKee M, Galea G, Stuckler D (2016) Unhealthy diets, obesity and time discounting: a systematic literature review and network analysis. Obes Rev 17:810-819. https://doi.org/10. 1111/obr.12431

Barlow P, McKee M, Reeves A, Galea G, Stuckler D (2017) Timediscounting and tobacco smoking: a systematic review and network analysis. Int J Epidemiol 46:860-869. https://doi.org/10.1093/ije/ dyw233

Barmby T (1998) The relationship between event history and discrete time duration models: an application to the analysis of personnel absenteeism. Oxf Bull Econ Stat 60:261-265

Bleichrodt H, Gao Y, Rohde KIM (2016) A measurement of decreasing impatience for health and money. J Risk Uncertain 52:213-231. https://doi.org/10.1007/s11166-016-9240-0

Bradford WD (2010) The association between individual time preferences and health maintenance habits. Med Decis Making 30:99112. https://doi.org/10.1177/0272989x09342276

Bradford D, Courtemanche C, Heutel G, McAlvanah P, Ruhm C (2014) Time preferences and consumer behavior. NBER Working Paper No. 20320, National Bureau of Economic Research, Cambridge, MA

Chabris CF, Laibson D, Morris CL, Schuldt JP, Taubinsky D (2008) Individual laboratory-measured discount rates predict field behavior. J Risk Uncertain 37:237. https://doi.org/10.1007/s11166-0089053-X

Courtemanche C, Heutel G, McAlvanah P (2015) Impatience, incentives and obesity. Econ J 125:1-31. https://doi.org/10.1111/ecoj.12124

Daugherty JR, Brase GL (2010) Taking time to be healthy: predicting health behaviors with delay discounting and time perspective. Pers Individ Dif 48:202-207. https://doi.org/10.1016/j.paid.2009.10.007

Downward P, Lera-Lopez F, Rasciute S (2011) The zero-inflated ordered probit approach to modelling sports participation. Econ Model 28: 2469-2477. https://doi.org/10.1016/j.econmod.2011.06.024

Eberth B, Smith MD (2010) Modelling the participation decision and duration of sporting activity in Scotland. Econ Model 27:822-834. https://doi.org/10.1016/j.econmod.2009.10.003
Farrell L, Shields MA (2002) Investigating the economic and demographic determinants of sporting participation in England. J R Stat Soc Ser A Stat Soc 165:335-348. https://doi.org/10.1111/1467-985X.00626

Frederick S, Loewenstein G, O'Donoghue T (2002) Time discounting and time preference: a critical review. J Econ Lit 40:351-401

Fredslund EK, Mørkbak MR, Gyrd-Hansen D (2018) Different domains - different time preferences? Soc Sci Med 207:97-105. https://doi. org/10.1016/j.socscimed.2018.04.052

Grignon M (2009) An empirical investigation of heterogeneity in time preferences and smoking behaviors. J Socio-Econ 38:739-751. https://doi.org/10.1016/j.socec.2009.05.003

Hovemann G, Wicker P (2009) Determinants of sport participation in the European Union. Eur J Sport Soc 6:51-59

Humphreys BR, Ruseski JE (2011) An economic analysis of participation and time spent in physical activity. BE J Econ Anal Pol 11:1-38

Humphreys B, Ruseski J, Li Z (2015) Physical activity, present bias, and habit formation: theory and evidence from longitudinal data. Working Paper No. 2015-6, University of Alberta, Edmonton, Canada

Hunter RF, Tang J, Hutchinson G, Chilton S, Holmes D, Kee F (2018) Association between time preference, present-bias and physical activity: implications for designing behavior change interventions. BMC Public Health 18:1388. https://doi.org/10.1186/s12889-0186305-9

Ikeda S, Kang M-I, Ohtake F (2010) Hyperbolic discounting, the sign effect, and the body mass index. J Health Econ 29:268-284. https:// doi.org/10.1016/j.jhealeco.2010.01.002

Kosteas VD (2015) Physical activity and time preference. Int J Health Econ Manag 15:361-386. https://doi.org/10.1007/s10754-0159173-1

Laibson D (1997) Golden eggs and hyperbolic discounting. Q J Econ 112:443-478. https://doi.org/10.1162/003355397555253

Lechner M (2009) Long-run labour market and health effects of individual sports activities. J Health Econ 28:839-854. https://doi.org/10. 1016/j.jhealeco.2009.05.003

Mørkbak MR, Gyrd-Hansen D, Kjær T (2017) Can present biasedness explain early onset of diabetes and subsequent disease progression? Exploring causal inference by linking survey and register data. Soc Sci Med 186:34-42. https://doi.org/10.1016/j.socscimed.2017.05. 050

Royer H, Stehr M, Sydnor J (2015) Incentives, commitments, and habit formation in exercise: evidence from a field experiment with workers at a Fortune-500 company. Am Econ J Appl Econ 7:5184. https://doi.org/10.1257/app.20130327

Shuval K, Drope J, Stoklosa M, Yaroch AL, Pachucki MC, Harding M (2017) Time preferences and physical activity: insights from behavioral economics. Health Behav Policy Rev 4:53-59. https://doi.org/ 10.14485/HBPR.4.1.6

Story G, Vlaev I, Seymour B, Darzi A, Dolan R (2014) Does temporal discounting explain unhealthy behavior? A systematic review and reinforcement learning perspective. Front Behav Neurosci 8:76. https://doi.org/10.3389/fnbeh.2014.00076

Sutton S (2018) Determinants of health-related behaviours: theoretical and methodological issues. In: Sutton S, Baum A, Johnston M (eds) The SAGE handbook of health psychology. SAGE Publications Ltd., London, pp 94-126. https://doi.org/10.4135/ 9781848608153.n4

van Stralen MM, De Vries H, Mudde AN, Bolman C, Lechner L (2009) Determinants of initiation and maintenance of physical activity among older adults: a literature review. Health Psychol Rev 3: 147-207. https://doi.org/10.1080/17437190903229462

Publisher's note Springer Nature remains neutral with regard to jurisdictional claims in published maps and institutional affiliations. 